\title{
Nutrient composition of Australian fast-food and fast-casual children's meals available in 2016 and changes in fast-food meals between 2010 and 2016
}

\author{
Lyndal Wellard-Cole ${ }^{1, *}\left(\mathbb{0}\right.$, Astrid Hooper ${ }^{2}$, Wendy L Watson ${ }^{1}$ and Clare Hughes ${ }^{1}$ \\ 'Nutrition Unit, Cancer Council NSW, 153 Dowling Street, Woolloomooloo, NSW 2011, Australia: ${ }^{2}$ School of \\ Medicine, Faculty of Science, Medicine and Health, The University of Wollongong, Wollongong, NSW, Australia
}

Submitted 19 September 2018: Final revision received 15 April 2019: Accepted 23 April 2019; First published online 12 September 2019

\begin{abstract}
Objective: A quarter of Australian children are overweight or obese. Research conducted in 2010 found that fast-food children's meals were energy-dense and nutrient-poor. Since then, menu labelling and self-regulation of marketing have been introduced in Australia. The present study aimed to: (i) investigate the nutrient composition of children's meals offered at fast-food chains; (ii) compare these with children's daily requirements and recommendations and the food industry's own criteria for healthier children's meals; and (iii) determine whether results have changed since last investigated in 2010.

Design: An audit of nutrition information for fast-food children's meals was conducted. Meals were compared with $30 \%$ (recommended contribution for a meal) and $100 \%$ of children's daily recommendations and requirements. A comparative analysis was conducted to determine if the proportion of meals that exceeded meal requirements and recommendations, and compliance with the food industry's own criteria, changed between 2010 and 2016.

Setting: Large Australian fast-food chains.

Participants: All possible children's meal combinations.

Results: Overall, 289 children's meals were included. Most exceeded 30\% of daily recommendations and requirements for a 4-year-old's energy, saturated fat, sugars and Na. Results were also substantial for 8- and 13-year-olds, particularly for Na. When compared with mean energy and nutrient contents from 2010, there were minimal changes overall.

Conclusions: Children's meals can provide excess energy, saturated fat, sugar and Na to children's diets. Systematic reformulation of energy, saturated fat, sugars and $\mathrm{Na}$ would improve the nutrient composition of the meals.
\end{abstract}

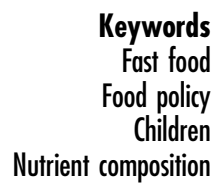

In Australia, $24.5 \%$ of children aged 2 to 14 years were overweight or obese in 2014-2015 ${ }^{(1)}$. A national survey found that up to $47 \%$ of 4 - to 13 -year-olds were regularly consuming more energy than required for their age group $^{(2)}$. More than a third of energy in the diets of Australian 4- to 8-year-olds (38\%) and 9- to 13-year-olds (39\%) came from energy-dense, nutrient-poor, or 'discretionary' foods ${ }^{(3)}$. Contributing to this excessive energy intake are fast foods, which are regularly consumed by school-aged children in Australia ${ }^{(4)}$. In 2015-2016, Australian households spent $13 \%$ of their weekly food and beverage budget on takeaway and fast foods ${ }^{(5)}$. Spending on takeaway and fast foods had increased by $50 \%$ between 2004-2005 and 2009-2010 ${ }^{(6)}$.
There are several initiatives that aim to address the impact of fast food on the population's diet. The fast-food industry has introduced the Quick Service Restaurant Industry (QSRI) Initiative for Responsible Advertising and Marketing to Children that aims 'to ensure that only food and beverages that represent healthier choices are promoted directly to children'(7). The QSRI has nutrient criteria for what constitutes a 'healthier' children's meal ${ }^{(7)}$. However, it is a voluntary initiative and the industry's own criteria are not aligned with government recommendations for children ${ }^{(8)}$. Additionally, in several Australian states and territories, fast-food chains with more than twenty outlets in the state or over fifty outlets nationally must display the energy content of menu items on menus 
and menu boards, along with the anchor statement 'the average daily energy intake is $8700 \mathrm{~kJ}^{(9-11)}$. It should be noted that this is an average adult's daily energy intake. One of the principles behind the implementation of menu labelling legislation was that it would encourage fast-food chains to reformulate menu items or offer healthier products as defaults ${ }^{(12)}$.

A study of children's fast-food meals in Australia found that nearly three-quarters of meals exceeded $30 \%$ of the daily energy recommendations for 4-year-old children and $90 \%$ of meals exceeded $30 \%$ of the upper limit for $\mathrm{Na}$ for children aged 4 to 8 years $^{(8)}$. A US study of twenty-two fast-food chains found that $99 \%$ of children's meals were of poor nutritional quality, with $44 \%$ exceeding standards for saturated and trans fats and $85 \%$ containing more than the recommended amount of $\mathrm{Na}^{(13)}$. Compared with children's meals from fast-food chains internationally, although Australian children's meals had similar energy contents to those from Canada, New Zealand and the UK, they had higher energy contents than children's meals in the USA ${ }^{(14)}$.

Providing healthier fast-food choices is one way of mitigating some of the negative effects of fast foods. Reformulation and restructuring of children's fast-food meals to include healthier menu items is needed to reduce the negative impact of fast foods on children's diets.

The previous analysis of Australian fast-food children's meals was conducted in $2010^{(8)}$ prior to the introduction of fast-food menu labelling. Whether the implementation of menu labelling has had any impact on fast foods in Australia is unknown. Therefore the aims of the present study were to: (i) investigate the nutrient composition of children's meals offered at fast-food chains; (ii) compare these with children's daily requirements and recommendations and the food industry's own criteria for healthier meals; and (iii) determine whether results have changed since last investigated in 2010.

\section{Methods}

\section{Sample}

An audit of fast-food nutrition information was conducted, both online and by request from customer service telephone numbers, emails or in-store from Australian fastfood chains. Chains were included if they provided meals marketed for children and were large enough to be covered by menu labelling laws; that is, they had twenty or more outlets in the state of New South Wales or fifty or more outlets nationally ${ }^{(9)}$.

For the purposes of the present study, children's meals were defined as small meals that were advertised in-store for consumption by children and comprised of a main item and a drink ${ }^{(7)}$. A total of twelve chains were included (see Table 1). Half were signatories to the QSRI and consisted of the more traditional fast-food chains (Chicken Treat,
Hungry Jack's, KFC, McDonald's, Oporto and Red Rooster); the others were not and were considered fast casual (Grill'd, The Coffee Club, Subway, Guzman Y Gomez, Jamaica Blue and Mad Mex). Although Subway can be considered a traditional fast-food chain, at the time of the 2010 study it did not sell children's meals and was excluded. Subway also provides fully customisable and made-toorder sandwiches, which are more aligned with the fastcasual chain menus than fast-food menus. To ensure consistency with the results, Subway has been included in the fast-casual category. Since the 2010 study, demand for traditional fast-food chains has shifted towards more premium and/or healthier options available at fast-casual chains ${ }^{(15)}$. These additional chains were included in the present analysis to give a broader overview of children's meal options in chain outlets in Australia.

\section{Procedures}

Nutrition information for all available children's meal combinations from each chain was sourced from company websites in May 2016. Data were collected for energy ( $\mathrm{kJ} /$ serving), saturated fat ( $\mathrm{g} /$ serving), sugars ( $\mathrm{g} /$ serving) and $\mathrm{Na}(\mathrm{mg} / \mathrm{serving})$ for each menu item. A total was then calculated for each possible meal combination for each of the nutrients. Where data were not available on company websites, information was obtained from store visits, printed material, menu boards, or via telephone calls and emails to outlets. This was consistent with methods utilised in the 2010 study $^{(8)}$.

\section{Data analysis}

Nutrition information was compared with children's daily requirements and recommendations according to the Australian Nutrient Reference Values for energy and $\mathrm{Na}$ (upper limit) ${ }^{(16,17)}$ and the Australian Dietary Guidelines for saturated fat and sugars ${ }^{(18)}$. To remain consistent with the previously published analysis ${ }^{(8)}$ the estimated energy requirements for children aged 4,8 and 13 years were calculated using a physical activity level of 1.7 (light-moderately active) and averaged between genders. These ages and physical activity level were included as they are the cut-offs for the QSRI, and this allows comparison with the 2010 research. Further, the last Australian survey found that $84 \%$ of 2 - to 4 -year-olds met the recommendation for $3 \mathrm{~h}$ physical activity/ $\mathrm{d}^{(19)}$. Additionally, $60 \%$ of 5 - to 17 -year-olds met or exceeded the recommendation of $1 \mathrm{~h}$ physical activity/ $\mathrm{d}^{(19)}$. Nutrient composition for each meal combination was compared with $30 \%$ (recommended as a guide for the nutrient contribution of meals ${ }^{(20)}$ ) and $100 \%$ of estimated daily requirements and recommendations for 4-, 8- and 13-year-old children (Table 2). Meals from the QSRI signatory chains were also compared with the fastfood industry's own nutrition criteria for healthier children's meals ${ }^{(7)}$. 
Table 1 Fast-food and fast-casual chains included in the present study

\begin{tabular}{ll}
\hline Chain & Description \\
\hline $\begin{array}{l}\text { Traditional fast-food chains } \\
\text { Chicken Treat }\end{array}$ & $\begin{array}{l}\text { Australian fried chicken chain } \\
\text { Hungry Jack's }\end{array}$ \\
KFC & Murger chain, known as Burger King in other countries \\
McDonald's & Multinational buried chicken chain \\
Oporto & Australian roasted chicken chain \\
Red Rooster & Australian roasted chicken chain \\
Fast-casual chains & Australian gourmet burger chain \\
Grill'd & Australian café chain serving hot and cold drinks and restaurant-style food \\
The Coffee Club & Multinational sandwich chain \\
Subway & Multinational Mexican food chain operating mostly in Australia and Asia \\
Guzman Y Gomez & Australian café chain serving hot and cold drinks and sandwiches and pastries \\
Jamaica Blue & Australian Mexican food chain \\
Mad Mex &
\end{tabular}

Table 2 Children's meal and daily requirements and recommendations, and the QSRI criteria used to assess children's fast-food meals

\begin{tabular}{|c|c|c|c|c|c|c|c|c|c|}
\hline & \multicolumn{3}{|c|}{ 4-year-olds } & \multicolumn{3}{|c|}{ 8-year-olds } & \multicolumn{3}{|c|}{ 13-year-olds } \\
\hline & Meal $^{*}$ & Daily & QSRI† & Meal $^{*}$ & Daily & QSRI† & Meal $^{*}$ & Daily & QSRI† \\
\hline Energy $\ddagger$ (kJ) & 1808 & 6025 & 2080 & 2258 & 7525 & 2080 & 3008 & 10025 & 2770 \\
\hline Saturated fat§ (g) & $4 \cdot 8$ & 16 & 8.3 & 6 & 20 & 8.3 & $8 \cdot 1$ & 27 & $11 \cdot 1$ \\
\hline Sugars \| (g) & 22.5 & 75 & 37.4 & 28 & 94 & 37.4 & 39 & 125 & 49.9 \\
\hline $\mathrm{Na}$ (mg) & 420 & 1400 & 650 & 420 & 1400 & 650 & 600 & 2000 & 650 \\
\hline
\end{tabular}

QSRI, Quick Service Restaurant Industry Initiative for Responsible Advertising and Marketing to Children.

${ }^{*}$ Meal recommendations are $30 \%$ of daily requirements.

TQSRI ${ }^{(7)}$ maximum nutrient criteria.

$\ddagger$ Nutrient Reference Values for Australia and New Zealand ${ }^{(17)}$, physical activity level of 1.7 (light-moderate activity), average for males and females.

§Australian Dietary Guidelines, saturated fat should comprise no more than $10 \%$ total energy intake ${ }^{(18)}$.

$\|$ Australian Dietary Guidelines, sugar should comprise no more than $20 \%$ total energy intake ${ }^{(18)}$.

IN $\mathrm{Na}$ upper limit, Nutrient Reference Values for Australia and New Zealand ${ }^{(16)}$

The number and proportion of total meals that met or exceeded each criterion were calculated. The mean and range per serving for each chain, each meal type and in total were calculated for energy and each nutrient.

Differences in median nutrient composition between traditional fast-food and fast-casual chains were investigated. As the data contained several outliers (energy and $\mathrm{Na}$ ) or were not normally distributed (sugars and saturated fat), Mann-Whitney $U$ tests were conducted.

Data were analysed using the statistical software package IBM SPSS Statistics version 19. A comparative analysis was conducted on the six signatory chains of the QSRI, by comparing with the 2010 analysis ${ }^{(8)}$. First, a sensitivity analysis using a Mann-Whitney test was conducted using all QSRI meals at both time points. As there were no significant differences in energy or any nutrient between 2010 and 2016 and there were no new meal options added by the chains in 2016, only the meals available at both time points from the signatory chains were included in the following analysis ( $n$ 144). Chi-square tests were conducted to determine whether the proportion of meals that met or did not meet the QSRI criteria, and the proportion of meals exceeding $30 \%$ and $100 \%$ of children's daily recommendations, had changed between 2010 and 2016. All results were considered significant if $P \leq 0.05$.

\section{Results}

The nutrient contents of 289 children's meals were reviewed, including 172 from QSRI signatory chains (60\%) and 117 from non-signatory chains ( $40 \%$ ). The mean nutrient composition of a children's meal was $2107 \mathrm{~kJ}, 6.4 \mathrm{~g}$ saturated fat, $26 \cdot 2 \mathrm{~g}$ sugars and $731 \mathrm{mg} \mathrm{Na}$ per serving (Table 3).

\section{Proportion of meals exceeding $30 \%$ and $100 \%$ of daily recommendations}

The majority of meals available from QSRI signatories exceeded $30 \%$ of daily recommendations for a 4-year-old's energy ( $69 \%, n$ 118), saturated fat $(52 \%, n 90)$, sugars $(67 \%, n 115)$ and upper level of intake for $\mathrm{Na}(88 \%$, $n$ 152; Table 4). The results were also substantial for 8- and 13-year-olds, particularly for $\mathrm{Na}(88 \%, n 152$ and $64 \%$, $n$ 110, respectively). Two meals exceeded $100 \%$ of the upper limit for $\mathrm{Na}$ for 4- and 8-year-olds. 
Table 3 Mean and range nutrients in Australian fast-food and fast-casual children's meals in 2016, per serving

\begin{tabular}{|c|c|c|c|c|c|c|c|c|c|}
\hline \multirow[b]{2}{*}{ Chain } & \multirow[b]{2}{*}{ No. of meals } & \multicolumn{2}{|c|}{ Energy (kJ) } & \multicolumn{2}{|c|}{ Saturated fat $(\mathrm{g})$} & \multicolumn{2}{|c|}{ Sugars (g) } & \multicolumn{2}{|c|}{$\mathrm{Na}(\mathrm{mg})$} \\
\hline & & Mean & Range & Mean & Range & Mean & Range & Mean & Range \\
\hline \multicolumn{10}{|l|}{ QSRI signatory chains } \\
\hline Chicken Treat & 4 & 2420 & 1689-3090 & 5.5 & $4 \cdot 1-7 \cdot 2$ & $33 \cdot 4$ & $30 \cdot 5-37 \cdot 2$ & 966 & $700-1290$ \\
\hline Hungry Jack's & 6 & 2495 & $1628-3250$ & $5 \cdot 6$ & $2 \cdot 8-8 \cdot 3$ & $27 \cdot 2$ & $0.5-50.5$ & 923 & $748-1093$ \\
\hline $\mathrm{KFC}$ & 2 & 1758 & 1296-2220 & 2.5 & $2 \cdot 2-2 \cdot 7$ & $18 \cdot 1$ & $16 \cdot 1-20 \cdot 1$ & 537 & $321-752$ \\
\hline McDonald's & 144 & 2167 & $735-3540$ & $5 \cdot 4$ & $1.4-12.5$ & 28.4 & $0.5-53 \cdot 2$ & 632 & $227-1168$ \\
\hline Oporto & 6 & 2803 & $2250-3635$ & 5.9 & $4 \cdot 7-6 \cdot 7$ & $16 \cdot 2$ & $0.7-32.5$ & 1184 & $989-1526$ \\
\hline Red Rooster & 10 & 1997 & $1410-2710$ & 3.6 & $2 \cdot 1-5 \cdot 6$ & 9.8 & $0.8-19.8$ & 816 & $675-1123$ \\
\hline All QSRI chains & 172 & 2192 & $735-3635 \dagger$ & $5 \cdot 3$ & $1.4-12.5 \ddagger$ & $26 \cdot 9$ & $0.5-53 \cdot 2$ & 679 & $227-1526$ \\
\hline \multicolumn{10}{|c|}{ Non-QSRI signatory chains } \\
\hline Grill'd & 4 & 1825 & 1560-2090 & 5.9 & $4 \cdot 9-6 \cdot 9$ & $14 \cdot 7$ & $3 \cdot 6-25 \cdot 8$ & 692 & $612-771$ \\
\hline Guzman Y Gomez & 21 & 2629 & $1378-3914$ & $12 \cdot 8$ & $10 \cdot 4-15 \cdot 0$ & 29.4 & $0.4-45 \cdot 8$ & 728 & $448-1076$ \\
\hline Jamaica Blue & 48 & 1667 & $911-2580$ & $6 \cdot 6$ & $2 \cdot 9-17 \cdot 1$ & $26 \cdot 0$ & $2 \cdot 0-61 \cdot 1$ & 625 & $410-1007$ \\
\hline Mad Mex & 12 & 2243 & 1578-2702 & 8.5 & $7 \cdot 0-9 \cdot 7$ & $36 \cdot 0$ & $1 \cdot 2-51.5$ & 728 & $664-804$ \\
\hline Subway* & 4 & 934 & $836-989$ & 0.5 & $0.2-0.7$ & $18 \cdot 0$ & $17 \cdot 6-18 \cdot 3$ & 327 & $171-401$ \\
\hline The Coffee Club & 28 & 2097 & 1185-3265 & 8.0 & $2 \cdot 0-20 \cdot 0$ & $19 \cdot 0$ & $2 \cdot 0-76 \cdot 0$ & 1301 & $330-2589$ \\
\hline All non-QSRI chains & 117 & 1982 & 836-3914† & $8 \cdot 0$ & $0.2-20.0 \ddagger$ & $25 \cdot 3$ & $0.4-76.0$ & 808 & $171-2589$ \\
\hline All chains & 289 & 2107 & $735-3914$ & $6 \cdot 4$ & $0.2-20.0$ & $26 \cdot 2$ & $0.4-76.0$ & 731 & $171-2589$ \\
\hline
\end{tabular}

QSRI, Quick Service Restaurant Industry Initiative for Responsible Advertising and Marketing to Children.

*Although Subway can be considered a fast-food chain, it has been included with fast casual as it was not included in the original study and provides a customisable menu more aligned with the other fast-casual chains.

†Fast-food meals significantly higher than fast casual, $P=0.003$

†Fast-food meals significantly lower than fast casual, $P<0.001$.

Table 4 Number and proportion of Australian fast-food and fast-casual children's meals from QSRI signatory chains and non-signatory chains ('other') exceeding $30 \%$ and $100 \%$ of estimated daily requirements and recommendations and the QSRI criteria

\begin{tabular}{|c|c|c|c|c|c|c|c|c|c|c|c|c|c|c|c|c|c|c|}
\hline & \multicolumn{4}{|c|}{ Energy } & \multicolumn{4}{|c|}{ Saturated fat } & \multicolumn{4}{|c|}{ Sugars } & \multicolumn{4}{|c|}{$\mathrm{Na}$} & \multirow{2}{*}{\multicolumn{2}{|c|}{$\begin{array}{c}\begin{array}{c}\text { Exceed } \\
\text { all QSRI } \\
\text { criteria* }\end{array} \\
\begin{array}{c}\text { QSRI } \\
(n 172)\end{array}\end{array}$}} \\
\hline & \multicolumn{2}{|c|}{$\begin{array}{c}\text { QSRI } \\
(n 172)\end{array}$} & \multicolumn{2}{|c|}{$\begin{array}{c}\text { Other } \\
(n 117)\end{array}$} & \multicolumn{2}{|c|}{$\begin{array}{c}\text { QSRI } \\
(n 172)\end{array}$} & \multicolumn{2}{|c|}{$\begin{array}{l}\text { Other } \\
(n 117)\end{array}$} & \multicolumn{2}{|c|}{$\begin{array}{l}\text { QSRI } \\
(n 172)\end{array}$} & \multicolumn{2}{|c|}{$\begin{array}{l}\text { Other } \\
(n 117)\end{array}$} & \multicolumn{2}{|c|}{$\begin{array}{l}\text { QSRI } \\
(n 172)\end{array}$} & \multicolumn{2}{|c|}{$\begin{array}{l}\text { Other } \\
(n 117)\end{array}$} & & \\
\hline & $n$ & $\%$ & $n$ & $\%$ & $n$ & $\%$ & $n$ & $\%$ & $n$ & $\%$ & $n$ & $\%$ & $n$ & $\%$ & $n$ & $\%$ & $n$ & $\%$ \\
\hline \multicolumn{19}{|c|}{ Meals exceeding $30 \%$ of estimated requirements and recommendations } \\
\hline 4-year-olds & 118 & 69 & 70 & 60 & 90 & 52 & 83 & 71 & 115 & 67 & 72 & 62 & 152 & 88 & 105 & 90 & - & \\
\hline 8 -year-olds & 76 & 44 & 37 & 32 & 65 & 38 & 73 & 62 & 93 & 54 & 59 & 50 & 152 & 88 & 105 & 90 & - & \\
\hline 13-year-olds & 20 & 12 & 6 & 5 & 24 & 14 & 37 & 32 & 46 & 27 & 43 & 37 & 110 & 64 & 36 & 31 & - & \\
\hline \multicolumn{19}{|c|}{ Meals exceeding $100 \%$ of estimated requirements and recommendations } \\
\hline 4-year-olds & 0 & 0 & 0 & 0 & 0 & 0 & 1 & 1 & 0 & 0 & 1 & 1 & 2 & 1 & 15 & 13 & - & \\
\hline 8-year-olds & 0 & 0 & 0 & 0 & 0 & 0 & 0 & 0 & 0 & 0 & 0 & 0 & 2 & 1 & 15 & 13 & - & \\
\hline 13-year-olds & 0 & 0 & 0 & 0 & 0 & 0 & 0 & 0 & 0 & 0 & 0 & 0 & 0 & 0 & 5 & 4 & - & \\
\hline \multicolumn{19}{|c|}{ Meals exceeding QSRI criteria } \\
\hline 4- to 8-year-olds & 95 & 55 & - & & $7 \dagger$ & $4 \dagger$ & - & & $48 \dagger$ & $28 \dagger$ & - & & $99 \dagger$ & $58 \dagger$ & - & & 141 & 82 \\
\hline 9 - to 13-year-olds & 30 & 17 & - & & & & - & & & & - & & & & - & & 131 & 76 \\
\hline
\end{tabular}

QSRI, Quick Service Restaurant Industry Initiative for Responsible Advertising and Marketing to Children.

$\left.{ }^{*} \mathrm{QSR}\right|^{(7)}$ maximum nutrient criteria.

†4- to 13-year-olds.

In non-signatory chains, a higher proportion of meals exceeded $30 \%$ of daily recommendations for saturated fat for all ages $(71 \%, n 83,62 \%, n 73$ and $32 \%, n 37$ for 4-, 8- and 13-year-olds, respectively). Fewer meals from other chains exceeded the $30 \%$ of energy recommendations for all ages, and the sugar recommendations for 4- and 8-year-olds; however, a higher proportion of meals from other chains exceeded $30 \%$ of a 13 -year-old's sugar recommendations. More meals from other chains exceeded the entire daily $\mathrm{Na}$ recommendations for all ages.

\section{Proportion of meals from QSRI signatory chains that met the QSRI criteria}

Overall, $82 \%$ of meals from QSRI signatories ( $n$ 141) exceeded the industry's own advertising and marketing nutrient criteria for energy and three nutrients for 4- to 8-year-old children as did $76 \%$ of meals ( $n$ 131) for 9- to 13 -year-olds. The proportion of meals exceeding an individual criterion was highest for $\mathrm{Na}$, with more than half of meals $(58 \%, n$ 99) exceeding this nutrient criterion (Table 4). Meals that met the criteria were most likely to include water, intensely sweetened soft drink or flavoured 
Table 5 Mean and range of nutrient content of Australian fast-food children's meals per serving from QSRI signatory chains in 2010 and 2016

\begin{tabular}{|c|c|c|c|c|c|c|c|c|c|c|}
\hline \multirow[b]{2}{*}{ Chain } & \multirow[b]{2}{*}{ No. of meals } & \multirow[b]{2}{*}{ Year } & \multicolumn{2}{|c|}{ Energy (kJ) } & \multicolumn{2}{|c|}{ Saturated fat $(\mathrm{g})$} & \multicolumn{2}{|c|}{ Sugars $(\mathrm{g})$} & \multicolumn{2}{|c|}{$\mathrm{Na}(\mathrm{mg})$} \\
\hline & & & Mean & Range & Mean & Range & Mean & Range & Mean & Range \\
\hline \multirow{2}{*}{ Chicken Treat } & 4 & 2010 & 3020 & $1228-4359$ & 14.9 & $2 \cdot 0-22 \cdot 0$ & $30 \cdot 4$ & $29 \cdot 4-31.7$ & 1087 & $817-1789$ \\
\hline & 4 & 2016 & 2420 & $1689-3090$ & $5 \cdot 5$ & $4 \cdot 1-7 \cdot 2$ & 33.4 & $30.5-37.2$ & 966 & $700-1290$ \\
\hline \multirow{2}{*}{ Hungry Jack's } & 2 & 2010 & 2469 & 2082-2855 & $7 \cdot 3$ & $5 \cdot 8-8 \cdot 8$ & $39 \cdot 1$ & $36 \cdot 6-41 \cdot 6$ & 755 & $572-937$ \\
\hline & & 2016 & 2814 & $2378-3250$ & $5 \cdot 6$ & $2 \cdot 8-8 \cdot 3$ & $47 \cdot 7$ & $44 \cdot 8-50 \cdot 5$ & 942 & $790-1093$ \\
\hline \multirow[t]{2}{*}{ KFC } & 1 & 2010 & 2350 & - & $12 \cdot 7$ & - & $19 \cdot 7$ & - & 769 & - \\
\hline & & 2016 & 2220 & - & $2 \cdot 2$ & - & $16 \cdot 1$ & - & 752 & - \\
\hline \multirow[t]{2}{*}{ McDonald's } & 132 & 2010 & 2124 & $735-3470$ & $5 \cdot 2$ & $1 \cdot 4-12 \cdot 2$ & $28 \cdot 6$ & $0 \cdot 2-52 \cdot 0$ & 643 & $222-1240$ \\
\hline & & 2016 & 2016 & $735-3540$ & $5 \cdot 3$ & $1 \cdot 4-12.5$ & $28 \cdot 7$ & $0.5-53.2$ & 631 & $227-1168$ \\
\hline \multirow[t]{2}{*}{ Oporto } & 2 & 2010 & 2620 & $2350-2890$ & $5 \cdot 7$ & $5 \cdot 6-5 \cdot 8$ & $20 \cdot 6$ & $5 \cdot 2-36 \cdot 0$ & 915 & $914-917$ \\
\hline & & 2016 & 2503 & $2250-2755$ & $6 \cdot 3$ & - & $18 \cdot 4$ & $4 \cdot 2-32.5$ & 990 & $989-991$ \\
\hline \multirow[t]{2}{*}{ Red Rooster } & 3 & 2010 & 2690 & $2328-3228$ & $5 \cdot 2$ & $4 \cdot 3-6 \cdot 8$ & $29 \cdot 9$ & $29 \cdot 8-30 \cdot 0$ & 879 & $624-1076$ \\
\hline & & 2016 & 2280 & $1990-2710$ & $4 \cdot 2$ & $3 \cdot 2-5 \cdot 6$ & $18 \cdot 1$ & $16 \cdot 5-19 \cdot 8$ & 877 & $693-1123$ \\
\hline \multirow[t]{2}{*}{ All QSRI chains } & 144 & 2010 & 2174 & $735-4359$ & 5.5 & $1 \cdot 4-22 \cdot 0$ & $28 \cdot 6$ & $5 \cdot 2-52 \cdot 0$ & 666 & $222-1789$ \\
\hline & & 2016 & 2184 & $735-3540$ & $5 \cdot 3$ & $1 \cdot 4-12 \cdot 5$ & $28 \cdot 6$ & $0.5-53.2$ & 655 & $227-1290$ \\
\hline
\end{tabular}

QSRI, Quick Service Restaurant Industry Initiative for Responsible Advertising and Marketing to Children ${ }^{(7)}$.

milk as the beverage, and/or did not include deep fried sides, such as fries. No meals containing a cheeseburger met the QSRI criteria.

\section{Differences between traditional fast-food and fast-casual chains}

There were significant differences between children's meals from traditional fast-food and fast-casual chains. Although fast-food chain children's meals had significantly higher energy content (median: $2232 v .1927 \mathrm{~kJ}, U=7995$, $z=-2.965, P=0.003)$, they had significantly lower saturated fat content (median: $4.9 v .7 .5 \mathrm{~g}, U=13532, z=4.978$, $P<0.001)$. There were no significant differences between fast-food and fast-casual children's meals for median content of sugars $(P=0.33)$ or Na $(P=0 \cdot 36)$.

\section{Changes between 2010 and 2016}

Between 2010 and 2016, the overall mean nutrient content of meals per serving available at both time points changed very little (Table 5). However, considering individual chains, there were some changes to note. Meals from Chicken Treat reduced in mean energy ( $-600 \mathrm{~kJ} /$ serving), saturated fat (-9.4 g/serving) and $\mathrm{Na}(-121 \mathrm{mg} /$ serving $)$, and meals from Red Rooster reduced in mean energy $(-410 \mathrm{~kJ} /$ serving $)$ and sugars $(-11.8 \mathrm{~g} /$ serving $)$. Meals from $\mathrm{KFC}$ reduced in saturated fat $(-10.5 \mathrm{~g} /$ serving $)$. Despite decreasing in saturated fat $(-1.7 \mathrm{~g} /$ serving $)$, meals from Hungry Jack's increased in energy $(+345 \mathrm{~kJ} /$ serving $)$, sugars $(+8.6 \mathrm{~g} /$ serving $)$ and $\mathrm{Na}(+187 \mathrm{mg} /$ serving $)$.

Between 2010 and 2016, there were no significant differences in the proportion of meals that did not meet the QSRI's criteria for any nutrient (all $P>0 \cdot 05$, data not shown). There were also no significant differences in the proportion of meals that exceeded either $30 \%$ or $100 \%$ of children's recommendations for energy or any nutrient (all $P>0.05$, data not shown).

\section{Discussion}

Our study aimed to investigate the nutrient composition of children's meals offered at Australian fast-food and fast-casual chains, compare the nutrient composition with children's requirements and recommendations, and determine whether there had been changes in nutrient composition between 2010 and 2016. While there was wide variation in nutrient composition within and between outlets, the mean meal was found to provide $2107 \mathrm{~kJ}, 6.4 \mathrm{~g}$ saturated fat, $26.2 \mathrm{~g}$ sugars and $731 \mathrm{mg} \mathrm{Na}$. This was above $30 \%$ of estimated daily requirements across all nutrients for a 4-year-old. The mean meal also contained greater than $30 \%$ of the upper limit of $\mathrm{Na}$ across all age groups. We found minimal changes in energy, saturated fat and Na contents of meals available in both 2010 and 2016, meaning that chains have not systematically reformulated their meals to make them healthier.

In Australia, $20 \%$ of children consume fast food at least once per week ${ }^{(4)}$. This increases to $34 \%$ in some cultural groups and $33 \%$ in children with an obese $\mathrm{BMI}^{(4)}$. Many of the meals included in our study supplied over $30 \%$ of daily energy requirements, which has been recommended as a guide for lunch or dinner meals ${ }^{(20)}$. In addition, many of the meals are providing excess saturated fat, sugars and $\mathrm{Na}$ which have the potential to displace nutrient-dense foods in a child's diet ${ }^{(21)}$. This may lead to weight gain in the long term.

Our study provides further evidence that in Australia, the introduction of menu labelling in chain outlets has not driven reformulation. The 2010 data were collected prior to the implementation of menu labelling in any Australian state ${ }^{(9)}$. The 2016 data were collected 5 years after the first state had implemented legislation to make energy labelling mandatory in chain outlets ${ }^{(9)}$. To provide customers with the ability to compare items, especially those with similar energy contents but different 
macronutrient contents, detailed nutrition information should be provided at the point of purchase for all items on the menu.

In QSRI chains, the majority of children's meals did not meet the industry's own definition of a healthy children's meal that could be marketed to children. Less than a quarter of meals would be permitted to be marketed to 9- to 13-year-old children and only 18\% could be marketed to younger children. Despite this, fast-food chains continue to market their children's meals by showing imagery only of the limited, 'healthier' options ${ }^{(22)}$. It is unknown how popular these options are. Further, the criteria themselves have their own limitations. As the saturated fat and sugar cut-offs are determined per $100 \mathrm{~kJ}$ it is harder for lowerenergy children's meals to meet the saturated fat and sugar criteria. That is, the higher the energy content, the more saturated fat and sugars the meal can contain. This allows chains to market their more energy-dense offerings but not their lower-energy meals. Overall, our study shows there is still a need to revise the QSRI nutrition criteria to ensure that unhealthy meals are not being promoted to children.

The participation of the fast-food chains in the QSRI can be perceived as activity that promotes health. Similarly, providing 'healthier' menu options can lead to the chain being perceived as healthier overall ${ }^{(23)}$ despite still providing many unhealthy options as was seen in our study. Further, in Australia fast-casual chains often market themselves as 'healthier' alternatives to traditional fast-food chains. For example, the Mexican fast-casual chain Guzman Y Gomez markets itself as 'Deliciously

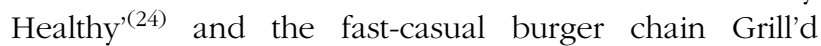
'Healthy Burgers' has an endorsement by a popular nutritionist and nutrient content claims on its website ${ }^{(25)}$. Although lower in energy, children's meals at fast-casual chains were found to be higher in mean saturated fat per meal than their traditional fast-food counterparts. Similarly, US studies found that menu items in children's meals from fast-casual outlets ${ }^{(26)}$ and sit-down restaurants ${ }^{(27)}$ had significantly more energy and other nutrients of public health concern than traditional fast-food menu items. Public education is required to ensure that consumers are not misled by such marketing approaches in either fast-food or fast-casual chains, and greater transparency on the nutrient composition of children's meals (in addition to energy) may counter the 'health haloes' chains may gain from participating in these activities.

However, education in isolation is not likely to result in healthier behaviours. To reduce the negative impact of fastfood meals on children's dietary intakes, the trend of increased energy, saturated fat and Na must be reversed. Reformulation of menu items has consistently been recommended to reduce the impact of unhealthy meals on nutritional intake in the fast-food setting ${ }^{(8,14,28,29)}$. Given the unhealthy nature of the meals offered by chains demonstrated in our study, reformulation remains an intervention that should be implemented.
Our results are similar to recent research conducted in the USA that found that despite publicly committing to reformulating the nutrient composition of children's meals, there have been little changes in energy, saturated fat or $\mathrm{Na}$ between 2012 and 2015 ${ }^{(29)}$. More broadly, there have been little changes in energy or macronutrient content of individual fast-food menu items that have been consistently on menus for multiple years in the $\mathrm{USA}^{(30,31)}$ or in Australia ${ }^{(32)}$.

Our study had several limitations. Most of the included nutrition information was sourced from chain websites and was not verified via laboratory testing, which would be cost-prohibitive due to the number of individual menu items, nutrients and samples required to be tested. Therefore, the accuracy of information is unknown. Another limitation was the exclusion of chains that do not market meals specifically for children. This excluded pizza chains, among others, where children share part of a larger meal. However, the complexities of portion sizes and large number of possible food combinations prohibited this analysis.

An additional limitation is that up to half of parents ordering for their 6- to 12-year-olds will choose larger options for their child rather than meals marketed as children's meals ${ }^{(33)}$. The nutritional impact of this has not been assessed; however, larger sizes would increase the energy and nutrient contents of the included items. Programmes such as Kids LiveWell in America have the potential for improving the nutrient composition of children's meals by offering smaller portions and healthier options ${ }^{(34)}$. However, research has shown that there was little improvement in nutrient content of children's meals in the three years following the introduction of Kids LiveWell ${ }^{(29)}$. Regardless of what meals were chosen for children, systematic reformulation would address this issue. However, to understand the impact that changes to nutrient composition makes, more accurate consumption data are required, particularly among children who are frequent consumers of children's fast-food meals. Further research that combines analysis based on fastfood consumption patterns of children of all ages together with the nutrient profile of the foods consumed is warranted.

\section{Conclusion}

The results of the present study show that the nutritional value of fast-food children's meals has not improved since 2010. Children's meals can provide excess energy, saturated fat, sugar and Na to children's diets. Systematic reformulation of energy content and the nutrients of public health concern would improve the nutrient composition of children's fast-food meals, thereby reducing the negative impact consumption of these meals may have on children's nutrient intake and overall diet. The fast-food industry's 
own nutrition criteria require review to appropriately define a healthy meal and ensure that unhealthy meals are not advertised to children.

\section{Acknowledgements}

Financial support: This research received no specific grant from any funding agency in the public, commercial or notfor-profit sectors. Conflict of interest: None declared. Authorship: L.W.-C. and C.H. conceived the study. C.H., L.W.-C. and W.L.W. designed and oversaw the study. A.H. collected and cleaned the data and conducted preliminary analysis. L.W.-C. and W.L.W. finalised the data analysis. L.W.-C. prepared the draft manuscript with input from A.H. and W.L.W. All authors provided significant input into manuscript review and approved the final manuscript. Ethics of human subject participation: The study did not require ethical approval as it was an observational study and had no human subjects.

\section{References}

1. Australian Bureau of Statistics (2015) 4364.0.55.001 National Health Survey: First Results, 2014-15. http:// www.abs.gov.au/ausstats/abs@.nsf/mf/4364.0.55.001?Open Document (accessed May 2016).

2. Commonwealth Scientific Industrial Research Organisation \& University of South Australia (2007) 2007 Australian National Children's Nutrition and Physical Activity Survey. Canberra, ACT: Commonwealth of Australia.

3. Australian Bureau of Statistics (2014) 4364.0.55.007 Australian Health Survey: Nutrition First Results - Foods and Nutrients 2011-12. http://www.abs.gov.au/ausstats/ abs@.nsf/Lookup/4364.0.55.007main+features12011-12 (accessed July 2019).

4. Hardy LL, Mihrshahi S, Drayton BA et al. (2016) NSW Schools Physical Activity and Nutrition Survey (SPANS) 2015: Full Report. Sydney, NSW: NSW Department of Health.

5. Australian Bureau of Statistics (2017) 6530.0 - Household Expenditure Survey, Australia: Summary of Results, 201516. Canberra: Australian Bureau of Statistics. http://www. abs.gov.au/ausstats/abs@.nsf/Lookup/6530.0main+features 12015-16 (accessed July 2019).

6. Australian Bureau of Statistics (2011) 6530.0 - Household Expenditure Survey Australia: Summary of Results 2009-10. http://www.abs.gov.au/ausstats/abs@.nsf/mf/65 30.0/ (accessed May 2016).

7. Australian Food and Grocery Council (2014) Quick service restaurant initiative for responsible advertising and marketing to children: AFGC. http://www.afgc.org.au/our-expertise/ health-nutrition-and-scientific-affairs/advertising-to-children/ (accessed October 2016).

8. Wellard L, Glasson C \& Chapman K (2012) Fries or a fruit bag? Investigating the nutritional composition of fast food children's meals. Appetite 58, 105-110.

9. NSW Government (2018) Food Act 2003. http://www. legislation.nsw.gov.au/viewtop/inforce/act+43+2003+FIRST+ 0+N (accessed August 2018).

10. Government of South Australia (2012) Food variation regulations 2012. https://www.legislation.sa.gov.au/LZ/V/R/2012/
FOOD\%20VARIATION\%20REGULATIONS\%202012_7.aspx (accessed December 2017).

11. ACT Parliamentary Counsel (2015) Food Act 2001. http:// www.legislation.act.gov.au/a/2001-66/current/pdf/2001-66. pdf (accessed August 2018).

12. NSW Food Authority (2012) Review of Fast-food Labelling Requirements ('Fast Choices'). Silverwater, NSW: NSW Food Authority.

13. Batada A, Bruening M, Marchlewicz EH et al. (2012) Poor nutrition on the menu: children's meals at America's top chain restaurants. Child Obes. 8, 251-254.

14. Hobin E, White C, Li Y et al. (2013) Nutritional quality of food items on fast-food 'kids' menus': comparisons across countries and companies. Public Health Nutr 17, 2263-2269.

15. Vuong B (2018) IBISWorld Industry Report H4512. Fast Food and Takeaway Food Services in Australia. Melbourne, VIC: IBISWorld.

16. National Health and Medical Research Council (2017) Nutrient Reference Values for Australia and New Zealand | Sodium. https://www.nrv.gov.au/nutrients/sodium (accessed July 2019).

17. National Health and Medical Research Council (2017) Nutrient Reference Values for Australia and New Zealand | Dietary Energy. https://www.nrv.gov.au/dietary-energy (accessed July 2019)

18. National Health and Medical Research Council (2013) Australian Dietary Guidelines. Canberra, ACT: NHMRC.

19. Australian Bureau of Statistics (2013) 4364.0.55.004 Australian Health Survey: Physical Activity, 2011-12. http://www.abs.gov.au/ausstats/abs@.nsf/Lookup/4364.0. 55.004Chapter1002011-12 (accessed May 2016).

20. UK Department for Education and Skills (2006) Nutritional Standards for School Lunches and Other School Food. http://media.education.gov.uk/assets/files/pdf/s/school\%20 food $\% 20$ trust $\% 20-\% 20$ nutritional $\% 20$ standards $\% 20$ for $\% 20$ school\%20lunches.pdf (accessed July 2019).

21. Rangan AM, Randall D, Hector DJ et al. (2008) Consumption of 'extra' foods by Australian children: types, quantities and contribution to energy and nutrient intakes. Eur J Clin Nutr 62, 356-364.

22. Watson WL, Lau V, Wellard L et al. (2017) Advertising to children initiatives have not reduced unhealthy food advertising on Australian television. J Public Health (Oxf) 39, 787-792.

23. Chandon P \& Wansink B (2007) The biasing health halos of fast-food restaurant health claims: lower calorie estimates and higher side-dish consumption intentions. J Consum Res 34, 301-314.

24. Guzman Y Gomez Mexican Taqueria (2016) Nutritional information. https://www.guzmanygomez.com/the-food/ nutritional-info/ (accessed May 2016).

25. Grill'd (2017) What's in your burger? https://www.grilld. com.au/nutrition (accessed September 2017).

26. Schoffman DE, Davidson CR, Hales SB et al. (2016) The fastcasual conundrum: fast-casual restaurant entrées are higher in calories than fast food. J Acad Nutr Diet 116, 1606-1612.

27. Deierlein AL, Peat K \& Luz C (2015) Comparison of the nutrient content of children's menu items at US restaurant chains, 2010-2014. Nutr J 14, 80 .

28. Wootan MG (2012) Children's meals in restaurants: families need more help to make healthy choices. Child Obes $\mathbf{8}$, 31-33.

29. Moran AJ, Block JP, Goshev SG et al. (2017) Trends in nutrient content of children's menu items in US chain restaurants. Am J Prev Med 52, 284-291.

30. Jarlenski MP, Wolfson JA \& Bleich SN (2016) Macronutrient composition of menu offerings in fast food restaurants in the US. Am J Prev Med 51, e91-e97. 
31. Bleich SN, Wolfson JA \& Jarlenski MP (2016) Calorie changes in large chain restaurants. Am J Prev Med 50, e1-e8.

32. Wellard-Cole L, Goldsbury D, Havill M et al. (2018) Monitoring the changes to the nutrient composition of fast foods following the introduction of menu labelling in New South Wales, Australia: an observational study. Public Health Nutr 21, 1194-1199.
33. Harris JL, Schwartz MB, Brownell KD et al. (2010) Fast Food F.A.C.T.S. Evaluating Fast Food Nutrition and Marketing to Youth. Hartford, CT: Yale Rudd Centre for Food Policy and Obesity.

34. National Restaurant Association (2012) Kids LiveWell Program | About. https://www.restaurant.org/Industry-Impact/FoodHealthy-Living/Kids-LiveWell/About (accessed September 2017). 